\title{
Intestinal Parasitic Infection among Food Handlers in the Holy City of Makkah During Hajj Season 1428 Hegira (2007G)
}

\author{
Majed H. Wakid, PhD, Esam I. Azhar, PhD, \\ and Tariq A. Zafar ${ }^{1}$, PhD \\ Department of Medical Laboratories Technology, \\ Faculty of Applied Medicine Sciences, \\ King Abdulaziz University, Jeddah, and \\ ${ }^{1}$ The Custodian of the Two Holy Mosques Institute of Hajj Research \\ Umm Al-Qura University, Makkah, Saudi Arabia \\ mwakid@kau.edu.sa
}

\begin{abstract}
In the Holy City of Makkah, during Hajj "season 1428 Hegira (2007)", 504 food handlers from twenty one countries were investigated for the infection of intestinal parasites. Stool samples were examined by direct smear techniques; Ritchie concentration technique and trichrome permanent staining technique. Intestinal parasites were detected in $31.94 \%$ of food handlers. Fifteen different intestinal parasites were identified; Trichuris trichiura (10.70\%), Blastocystis hominis (9.33\%), Hook worms (7.54\%), Endolimax nana (6.15\%), Entamoeba coli (4.37\%), Entamoeba histolytica (2.78\%), Giardia lamblia (1.98\%), Entamoeba hartmanni (1.79\%), Schistosoma mansoni (1.59\%), Strongyloides stercoralis (1.00\%), Iodamoeba buetschlii (0.8\%), Ascaris lumbricoides (0.8\%), Hymenolepis nana $(0.6 \%)$, Dientamoeba fragilis $(0.2 \%)$ and Enterobius vermicularis $(0.2 \%)$. In conclusion, the high prevalence of intestinal parasitic infections suggest; stool analysis for intestinal parasites should be periodically carried out in addition to the sanitation education and health special care for food handlers working in Makkah. This study is the first during the Hajj season to investigate distribution of intestinal parasites among food handlers in The Holy City of Makkah.
\end{abstract}

Keywords: Intestinal parasites, Food handlers, Ritchie technique, Direct smears, Makkah.

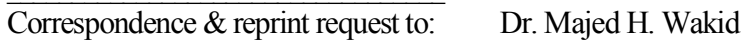

P.O. Box 80324 Jeddah 21589, Saudi Arabia

Accepted for Publication: 08 March 2009. Received: 23 November 2008. 


\section{Introduction}

Intestinal parasites are responsible for one of the major health problems with socio-economic effects in the world, especially in developed countries in tropical and sub tropical areas. Globally, due to intestinal parasitic infections, some 3.5 billion people are affected; 450 million are symptomatic and yearly more than 200,000 deaths are reported ${ }^{[1]}$.

Infection of food handlers with intestinal pathogens, including parasites could be a potential cause for the spreading of these pathogens to the people (the customers) or the surrounding community. In addition to the risk of illness to the food handlers themselves ${ }^{[2,3]}$.

The aim of this study was to examine for the first time the prevalence of intestinal parasites among food handlers in the Holy City of Makkah during the Hajj season.

\section{Materials and Methods}

\section{Setting}

This study was conducted during the Hajj season of 1428 Hegira (2007). Stool specimens were collected from food handlers working in restaurants, cafeterias and other food shops. The laboratory parasitological techniques were achieved in King Fahad Medical Research Centre at King Abdulaziz University in Jeddah, Saudi Arabia. The whole study was supervised by the Custodian of the Two Holy Mosques Institute of Hajj Research at Umm Al-Qura University in Makkah, with the cooperation from the community health general administration in Holy Makkah Municipality.

\section{Specimens}

During this study, stool samples were collected from 504 food handlers. Each food handler was provided with a clean sample container with collection instructions. Each food handler was interviewed regarding his nationality, age and other information according to the provided questionnaire (Fig. 1).

\section{Parasitological Methods}

Each stool specimen was examined macroscopically for color, consistency and presence of any macroscopic diagnostic stage of adult worms or segments. 


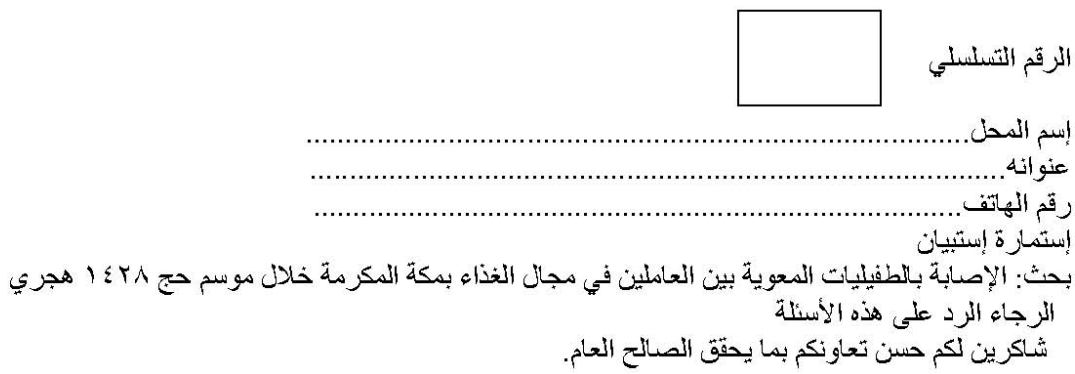

\begin{tabular}{|c|c|}
\hline Name & الإسم \\
\hline Age & الثعمر \\
\hline Nationality & |الجنسية \\
\hline Weight & الثوزن المن \\
\hline Height & الطول \\
\hline Years of residency in KSA & فترة الإقامة في اللسعودية لغير الكسعودي \\
\hline Resident & مكان ألإقامة \\
\hline$\square$ With your family & 1َ) عائتثك \\
\hline$\square$ With other workers & لـِّن مع عمال آخرين \\
\hline$\square$ Alone & ماصة \\
\hline Do you know what intestinal parasites are? & هل تعزت ماهي الطظفيليات ألمعوية" \\
\hline 口YES $\square$ NO & 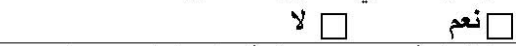 \\
\hline $\begin{array}{l}\text { Did you complain from abdominal } \\
\text { symptoms? }\end{array}$ & هل لديك أعراض معوية (ألم في البطن، إسهال....) \\
\hline QYES $\square$ NO & $\begin{array}{cc}\text { ע } \square \\
\end{array}$ \\
\hline $\begin{array}{l}\text { Do you think you are now infected with } \\
\text { intestinal parasites? }\end{array}$ & هل تعثقد أنتك الآن مصاب بطفيليات معوية؛؟ \\
\hline$\square$ YES $\square$ NO & ل $\square$ \\
\hline More information & أي إضافات أخرى \\
\hline
\end{tabular}

Fig. 1. Sample of the questionnaire.

\section{Direct Smears}

Saline direct smear is used mainly for detection of motility of intestinal protozoan trophozoites, which are seen in liquid or semi liquid specimens. Iodine direct smear shows the characteristic features of the diagnostic stages in more details. Generally, direct smear is cheap, easy and the best simple way for detection of microscopic cellular exudates including RBC's, WBC's and mucous. In case of light infections, direct smears might show false negative results and if the specimens are old, the parasites will die and can be overlooked ${ }^{[6]}$. Direct stool smears were performed by emulsifying about $2 \mathrm{mg}$ of stool uniformly in a drop or two 
of saline in the left side of microscope slide, and similarly in iodine in the right side. Preparation were covered with cover glasses $(22 \times 22 \mathrm{~mm})$ and scanned microscopically under low and high $(\times 10$ and $\times 40)$ objective lenses.

\section{Ritchie Sedimentation Technique}

Although, this formal ether technique cannot detect trophozoites, it is considered as the best concentration technique used in diagnostic parasitology laboratories for detection of cysts, ova and larvae $e^{[4,5]}$. Generally, $10 \%$ formal saline is used in Ritchie technique to kill and preserve diagnostic stages of the parasites. Diethyl ether collects most of unwanted debris in a separate layer. All diagnostic stages that are applicable with Ritchie technique will be concentrated at the bottom of the analysis centrifuge tube. However, safety precaution should be taken, as formalin is carcinogenic, and diethyl ether is flammable and explosive. Quantitatively, one slide from Ritchie technique is a substitute of about one thousand slides or more from the direct smear technique. Thus the greater amount of stool used, the greater the chance of recovery of diagnostic stages. Ritchie sedimentation technique was performed by emulsifying about $2 \mathrm{~g}$ of stool in $10-15 \mathrm{ml}$ of $10 \%(\mathrm{v} / \mathrm{v})$ formal-saline. The suspension was allowed to stand for $30 \mathrm{~min}$, then strained through two layers of gauze into a $15 \mathrm{ml}$ conical centrifuge tube and centrifuged at $2000 \mathrm{rpm}$ for $5 \mathrm{~min}$. When needed, washing step was repeated until supernatant becomes clear. The sediment was re-suspended with $10 \mathrm{ml}$ of $10 \%(\mathrm{v} / \mathrm{v})$ formal-saline and allowed to stand for 5-10 min. $3 \mathrm{ml}$ of diethyl ether was added, then the tube was shaken vigorously for $30 \mathrm{sec}$ and centrifuged at $2000 \mathrm{rpm}$ for $5 \mathrm{~min}$. After centrifugation, the applicable diagnostic stages were sedimented in the bottom of the tube. The fecal debris was separated in a layer between the diethyl ether and the $10 \%(\mathrm{v} / \mathrm{v})$ formal-saline layers. Fecal debris layer was loosened by wooden stick and the tube rapidly inverted to discard the top three layers while the sediment remained at the bottom. 1-2 drops of iodine were added to the sediment and mixed well. Then, part of the sediment was transferred to a microscope slide, covered with a cover glass $(22 \times 22$ $\mathrm{mm})$ and scanned microscopically under low and high $(\times 10$ and $\times 40)$ objective lenses. 


\section{Trichrome Staining}

The best way to diagnose non-motile trophozoites is by staining them and one of the best stains is trichrome stain. However, fixation step is very important in this technique; caution should be taken as Schaudinn's fixative is composed of highly toxic mercuric chloride. Trichrome permanent staining smear was prepared by spreading $20 \mathrm{mg}$ of stool on a microscope slide, then immediately fixed in Schaudinn's fixative. Smears were then placed in $70 \%$ ethanol for 5 min then in $70 \%$ ethanol plus iodine for 3-5 min. Smears were placed in two changes of $70 \%$ ethanol for 3-5 min each, followed by staining in trichrome stain solution for $10 \mathrm{~min}$. Destaining was in $90 \%$ ethanol plus acetic acid for 1 to 3 seconds ( 2 dips). Slides were dipped once in $95 \%$ ethanol then in $100 \%$ ethanol followed by two changes of $100 \%$ ethanol for $3-5 \mathrm{~min}$ each. Finally, smears were placed in two changes of xylene for 3-5 min each, and then were examined under light microscope using x 100 objectives.

\section{Statistical Analysis}

Statistical analysis of the data for this study was analysed using SPSS, version 13 software. The food handlers were classified according to nationalities into ten groups; Indians, Bangladeshi, Yemeni, Egyptian, Turkish, Afghani, Burmese, Syrian, Pakistani and others. The reference nationality was the Pakistani as it shows the lowest prevalence of intestinal parasites. The differences were considered to be statistically significant when the $p$ value was $<0.05$.

\section{Results}

\section{Food Handlers' Data}

The total number of food handlers was 504 (501 males and 3 females) with age range 17-70. Those food handlers were from twentyone countries (Table 1), as follows; $144(28.75 \%)$ from India, 132 (26.19\%) from Bangladesh, 57 (11.31\%) from Yemen, 37 (7.34\%) from Egypt, 28 (5.55\%) from Turkey, 24 (4.76\%) from Afghanistan, 19 (3.77\%) from Burma, 16 (3.17\%) from Syria, 12 (2.38\%) from Pakistan, 8 (1.59\%) from Sri Lanka, 6 (1.19\%) from Indonesia, and each of the remaining nationalities were less than $1 \%$, as follows; 5 from Niger, 4 from Philippine, 3 from Nigeria, 2 from Ethiopia, 2 from Mali, 1 from 
Lebanon, 1 from Nepal, 1 from Palestine, 1 from Saudi Arabia and 1 from Sudan. During this study we found that $71(14.09 \%)$ of food handlers live with their families, 37 (7.34\%) food handlers live alone each one in separate resident and the remaining 396 (78.57\%) food handlers live as groups. Regarding the years of residency in Saudi Arabia, $48.56 \%$ of food handlers arrived during the past five year, $22.12 \%$ arrived six to ten years ago, $11.54 \%$ arrived eleven to fifteen years ago, $14.80 \%$ arrived before more than fifteen years ago and the remaining 2.98\% were born and raised in Saudi Arabia.

\section{Macroscopic Examination}

The color of specimens ranged from yellowish, light brown, brown to greenish or dark brown. The consistency ranged from; soft to loose, three stool samples were watery and none was bloody. Only one sample from a Bangladeshi food handler contained live adult female worm of Enterobius vermicularis.

Table 1. Total number, percentage of infection in each nationality of food handlers.

\begin{tabular}{l|c|c|c|c}
\hline \multicolumn{1}{c|}{ Nationalities } & $\begin{array}{c}\text { Total Number of } \\
\text { Food Handlers }\end{array}$ & $\mathbf{\%}^{\mathbf{a}}$ & $\begin{array}{c}\text { Number of Infected } \\
\text { Food Handlers }\end{array}$ & $\mathbf{\%}^{\mathbf{b}}$ \\
\hline Indian & 144 & 28.57 & 30 & 20.83 \\
\hline Bangladeshi & 132 & 26.19 & 47 & 35.61 \\
\hline Yemeni & 57 & 11.31 & 26 & 45.61 \\
\hline Egyptian & 37 & 7.34 & 12 & 32.43 \\
\hline Turkish & 28 & 5.55 & 12 & 42.86 \\
\hline Afghan & 24 & 4.76 & 7 & 29.17 \\
\hline Burmese & 19 & 3.77 & 12 & 63.16 \\
\hline Syrian & 16 & 3.17 & 7 & 43.75 \\
\hline Pakistani & 12 & 2.38 & 2 & 16.67 \\
\hline Others (12 nationalities) & 35 & 6.94 & 8 & 22.86 \\
\hline a - calculated to the total number of 504 food handlers of all nationalities. & \\
b $\%$ - calculated to the total number of food handlers of the indicated nationality. &
\end{tabular}

\section{Microscopic Examination}

Out of the 504 food handlers, 161 (31.94\%) were infected with intestinal parasites (Table 1). Fifteen different intestinal parasites were detected from food handlers included in this study. These parasites are as follows according to the higher prevalence; Trichuris trichiura $(10.70 \%)$, Blastocystis hominis (9.33\%), Hook worms (7.54\%), Endolimax nana (6.15\%), Entamoeba coli (4.37\%), Entamoeba histolytica (2.78\%), Giardia lamblia (1.98\%), Entamoeba hartmanni (1.79\%), Schistosoma mansoni (1.59\%), Strongyloides stercoralis (1.00\%), Iodamoeba 
buetschlii (0.8\%), Ascaris lumbricoides (0.8\%), Hymenolepis nana $(0.6 \%)$, Dientamoeba fragilis $(0.2 \%)$ and Enterobius vermicularis $(0.2 \%)$. There was a significantly $(p<0.05)$ greater prevalence of parasites in Yemeni $(p=0.049)$ and Burmese $(p=0.011)$, while in the remaining nationalities, no statistically significant difference was observed. For example, in Indian $(p=0.73)$, in Bangladeshi $(p=0.15)$, in Egyptian $(p=0.17)$, in Turkish $(p=0.11)$, in Afghani $(p=0.35)$ and in Syrian $(p=0.13)$.

Using direct smears, $94(18.65 \%)$ samples out of the 504 samples were positive to parasitic infection. That positive represents $59 \%$ out of the total 161 positive samples. Direct smears have shown trophozoite stage of G. lamblia clearly in some samples. Amoeba trophozoites were seen but non-motile and then identified by trichrome stain. In 13 samples B. hominis was detected in direct smears and missed in Ritchie technique.

Using Ritchie technique, 156 (30.95\%) samples out of the 504 samples were positive to parasitic infection. That positive represents $96.9 \%$ out of the total 161 positive samples, as Ritchie technique was able to detect all the parasites, except the trophozoite stage of the intestinal protozoan parasites and 13 samples with $B$. hominis.

Trichrome stain was performed for all liquid or semi liquid stool samples mainly to confirm the protozoan trophozoite stages, which could not be seen in Ritchie technique and could be missed in direct smears.

\section{Discussion}

Infection of asymptomatic persons, especially workers dealing with food (food handlers), could become a potential cause of dissemination of variety of pathogens including intestinal parasites ${ }^{[2]}$.

In Saudi Arabia, studies of intestinal parasites in food handlers were limited and the present study is the first in the Holy City of Makkah to study intestinal parasites in food handlers. The study showed that the prevalence of intestinal parasites is high (31.94\%). The infected food handlers with both protozoan and helminths parasites were mainly from Asian countries (Table 1). The fifteen isolated parasites in the present study (Table 2) were compatible with Jeddah study ${ }^{[4]}$, but no Taenia saginata and Chilomastix mesnili were detected. The previous published Jeddah study in 2006 was the first in Saudi Arabia to investigate 
intestinal parasites among food handlers including Cryptosporidium ${ }^{[4]}$. One thousand and nine stool samples from non-Saudi food handlers working in Jeddah were examined by direct smears, Ritchie concentration technique, trichrome stain and Kinyoun's modified staining. Intestinal parasites (excluding Cryptosporidium) were detected in $50.15 \%$ of food handlers. Seventeen different intestinal parasites were identified; B. hominis (23.29\%), Hook worms (14.67\%), T. trichiura (9.61\%), E. nana (7.04\%), E. coli (5.05\%), G. lamblia (4.6\%), E. histolytica (2.97\%), E. hartmanni (2.97\%), S. stercoralis (1.88\%), I. buetschlii (1.29\%), S. mansoni (1.1\%), A. lumbricoides (1.1\%), H. nana $(0.8 \%)$, D. fragilis $(0.6 \%)$, T. saginata $(0.2 \%)$, E. vermicularis $(0.2 \%)$ and $C$. mesnili $(0.2 \%)$. Detected protozoa in the present study represented $53.33 \%$ of the total detected parasites and are transmitted via direct fecaloral rout. Pathogenic intestinal protozoa were E. histolytica and $G$. lamblia, while non-pathogenic were D. fragilis, E. coli, E. hartmanni, E. nana and $I$. buetschlii. B. hominis still uncertain pathogenic protozoa ${ }^{[6]}$. The infection with non-pathogenic organisms may indicate low standard of hygiene and similarly pathogenic organisms' infection could take place. Presently, the Holy City of Makkah study; Kinyoun's modified staining for Cryptosporidium oocysts was performed, but it is preferred not to show the result of high Cryptosporidium prevalence in the present article as the result of previous study in $\mathrm{Jeddah}^{[4]}$ is still under investigation by molecular techniques. Helminithic infection represented $46.67 \%$ of the total detected parasites. Nematoda infection with hookworms, $T$. trichiura and A. lumbricoides were the most common, as found in other studies ${ }^{[4,7-9]}$. E. vermicularis adult female pinworm was isolated from a Bangladeshi food handler; same result was found in a Jeddah study ${ }^{[4]}$, but scanty eggs for this parasite were detected in stool as pinworms usually lay eggs in perianal region and not while in their habitat in the intestine. For Trematoda and Cestoda Helminithic infection, $S$. mansoni and $H$. nana were limited in apparently healthy food handlers from Yemen and Egypt. Six Yemeni and two Egyptian food handlers were infected with intestinal bilharzias. On the other hand, two Yemeni and one Egyptian food handlers were infected with the dwarf tapeworm, which can easily cause both external and internal autoinfection. 


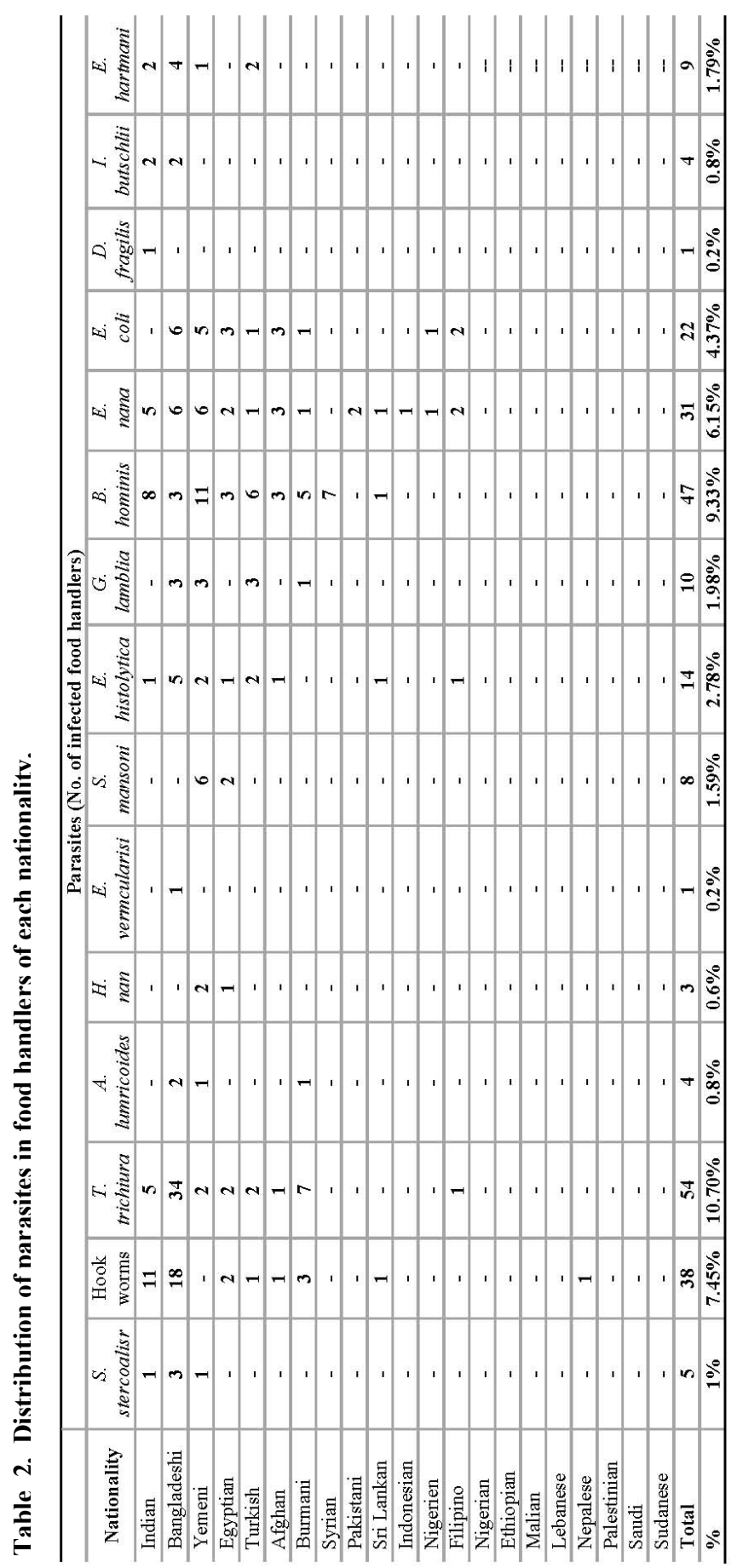


In an earlier study, in 1992, it was investigated the prevalence of intestinal parasites among 13216 male food handlers in King Abdulaziz Hospital in Al-Madinah ${ }^{[7]}$. The investigators found that approximately $14 \%$ of these individuals were infected with pathogenic parasites. The most common parasites were G. lamblia (33\%), E. histolytica $(23 \%), T$. trichiura (12.3\%) and A. lumbricoides (11.8\%). In 1987, Khan and others reported the prevalence of parasitic infection among 13136 food handlers in Dammam and Al-Khobar ${ }^{[8]}$ was 993 (7.56\%). The workers suggested that the parasite prevalence was low. The obvious reason (from our point of view) for their low prevalence is the use of direct wet mounts with all stool samples, but not concentration techniques. The workers found several pathogenic and non-pathogenic intestinal parasites: E. histolytica (3.17\%), G. lamblia (3.10\%), E. coli $(1.71 \%)$, I. buetschlii (1.32\%), E. nana (1.05\%), A. lumbricoides (0.6\%), Hookworms $(0.3 \%)$, T. trichiura $(5 \%)$, H. nana $(0.1 \%)$, S. mansoni $(0.03 \%)$, E. vermicularis $(0.02 \%)$, S. stercoralis $(0.01 \%)$, and T. saginata $(0.01 \%)$. In 1983, a study investigated fecal parasites in 203 non-Saudi catering and domestic staff at Riyadh Military Hospital ${ }^{[9]}$. Major isolated parasites were: T. trichiura (43.2\%), Hookworms (25.8\%), A. lumbricoides (15.2\%) and G. lamblia (14.4\%).

Several workers around the world studied the prevalence of intestinal parasites among food handlers since the area of sixties and seventies ${ }^{[10-15]}$, and during the recent twenty years. A one-year study in Irbid, Jordan by Al-Lahham et al. ${ }^{[16]}$ investigated 283 food handlers for intestinal parasite, Salmonella and Shigella. The study revealed that the food handlers, particularly non-Jordanian were a potential source of food-borne infection. By using direct wet mounts and formal ether concentration technique, many intestinal parasites were detected in the stool of the food handlers: $4.9 \%$ were infected with $A$. lumbricoides, $3.9 \%$ with G. lamblia, $2.8 \%$ with $S$. mansoni, $2.5 \%$ with Hookworms, $1.8 \%$ with $H$. nana, 1.1 with $T$. trichiura, $0.7 \%$ with $E$. histolytica and $0.4 \%$ with $T$. saginata. A group of 200 food-handlers in the Panama Canal area were involved in parasitological evaluation using direct wet mounts and Faust concentration technique ${ }^{[17]}$. The workers found several pathogenic and non-pathogenic intestinal parasites: G. lamblia $(25 \%), E$. coli (10\%), A. lumbricoides (9\%), T. trichiura (5\%), E. nana (4\%), I. buetschlii (3\%), hookworms (2\%), S. stercoralis (2\%), and C. mesnili (1\%). In 1991, a study in Jamaica on healthy food handlers carrier of 
HTLV-I was concerned with the infection of gastrointestinal parasites ${ }^{[18]}$. In that study the workers examined 212 samples of healthy Jamaican food-handlers. Using Ritchie stool techniques and Harada-Mori culture, the following parasites were detected: A. lumbricoides in $2.8 \%, T$. trichiura in $7.1 \%$, Hookworms in $6.1 \%, E$. coli in $21.8 \%$, while $E$. hartmanni, G. lamblia, E. nana, I. buetschlii and C. mesnili each in less than $10 \%$ of responders. Another study during a period of six years was accomplished in Tunis on 6092 stool samples from food handlers showed that the prevalence of intestinal parasites is $14.46 \%{ }^{[19]}$. The detected parasites were: E. histolytica $(23.27 \%)$, E. coli $(32.16 \%)$ G. lamblia, (22.61\%), E. nana (17.84\%), while H. nana, E. vermicularis, C. mesnili, Trichomonas intestinalis, T. saginata, A. lumbricoides, T. trichiura, S. stercoralis, hookworms and Enteromonas hominis was each in less than $5 \%$. After that, a work was published concerning the presence of intestinal parasites in school food handlers in 20 public elementary schools from various areas of the city of Uberlândia, Minas Gerais, Brazil $^{[20]}$. Stool samples from 104 female food handlers (cooks and their helpers) working in 20 public elementary schools were examined. These samples were processed by the Hoffmann, Pons and Janer method then the sediments were stained with iodine using triplicate slides. Intestinal parasites were detected in $85 \%$ of the 20 studied schools and in $47.1 \%$ of studied food handlers. Detected intestinal parasites included G. lamblia (21.1\%), E. coli (21.1\%), Hookworms (9.6\%), A. lumbricoides (5.8\%), E. histolytica $(2.9 \%), H$. nana (1.9\%) and S. stercoralis (1\%). Sadek and others studied the distribution of intestinal parasites among 1700 food handlers above 20 years of age in Qalubia, Al Qalyubiyah, in Egypt ${ }^{[21]}$. Different stool techniques were done including Faust, Ritchie and Kato techniques and test tube cultures for larvae. The prevalence of intestinal parasites was: E. coli (18\%), G. lamblia (16.76\%), I. buetschlii (15\%), B. hominis (12.5\%), E. histolytica $(9.76 \%)$, A. lumbricoides (7\%), while $S$. mansoni, Hookworms, T. trichiura, $H$. nana, S. stercoralis, $E$. vermicularis, C. mesnili, E. nana and T. hominis was each in less than 5\%. A study in Thailand screened 135 food handlers for parasites and bacteria $^{[22]}$. The stool examination for parasites was done by direct smear and formalin ether concentration method. 2.71\% were infected with Opisthorchis viverrini, $1.8 \%$ with hookworms, $0.9 \%$ with $G$. lamblia and $0.9 \%$ with $S$. stercoralis. 
In conclusion, revealing for first time during any Hajj season that the distribution of protozoan and Helminithic intestinal parasites are not uncommon in non-Saudi food handlers working in the Holy City of Makkah. Finally, we recommend stool examination for intestinal parasites by using both direct smears and formal ether technique every six months. Then, the infected food handlers should have effective treatment and a re-examination of stool. All these examinations should be a requirement before issuing health certificates. In addition, recommendation for further studies is advisable; about the role of water, soil, vegetables and fruits on spreading of intestinal parasites in Saudi Arabia. Clearly there is a need for public health education on proper hygiene and food handling practice.

\section{Acknowledgments}

This study was supported by The Custodian of the Two Holy Mosques Institute of Hajj Research at Umm Al-Qura University in Makkah, Saudi Arabia with cooperation from the community health general administration in the Holy Makkah Municipality. Appreciation is extended to King Fahd Medical Research Centre at King Abdulaziz University in Jeddah, Saudi Arabia for providing the place for practical work of this study. A special recognition is given to Mrs. M. Al Ghanmi and Mrs. I. Al Saadi for their assistance on this report. The authors would like to express thanks to Dr. B. Eldeek for his assistance in the statistical analysis of this study.

\section{References}

[1] World Health Organization home page, from Retrieved December 10, 2006 $<$ http://www.who.int/ctd/intpara/index.html $>$.

[2] Jones TF, Angulo FJ. Eating in restaurants: a risk factor for food borne disease? Clin Infect Dis 2006; 43(10): 1324-1328.

[3] Zain MM, Naing NN. Sociodemographic characteristics of food handlers and their knowledge, attitude and practice towards food sanitation: a preliminary report. Southeast Asian J Trop Med Public Health 2002; 33(2): 410-417.

[4] Wakid MH. Distribution of intestinal parasites among food handlers in Jeddah, Saudi Arabia. J Parasitic Dis 2006; 30(2): 146-152.

[5] Garcia LS. Diagnostic Medical Parasitology, Washington: ASM Press, 2007.

[6] Kuo HY, Chiang DH, Wang CC, Chen TL, Fung CP, Lin CP, Cho WL, Liu CY. Clinical significance of Blastocystis hominis: experience from a medical center in northern Taiwan. J Microbiol Immunol Infect 2008; 41(3): 222-226. 
[7] Ali SI, Jamal K, Qadri, SMH. Prevalence of intestinal parasites among food handlers in Al-Medinah. Ann Saudi Med 1992; 12(1): 63-66.

[8] Khan ZA, Al-Jama AA, Madan I. Parasitic infections among food handlers in Dammam and Al-Kobar, Saudi Arabia. Ann Saudi Med 1987; 7(1): 47-50.

[9] Abu Al Saud AS. Faecal parasites in non-Saudi catering and domestic staff at the Riyadh Military Hospital. Saudi Med J 1983; 4(3): 259-262.

[10] WILKS NE, SONNENBERG B. Intestinal parasites in food handlers returned from Korea. Am J Trop Med Hyg 1954; 3(1): 131-135.

[11] Ninu E. [The spreading of intestinal parasitoses in Arezzo province. Parasitologic and bacteriologic findings in a group of food handlers] Nuovi Ann Ig Microbiol 1965; 16(6): 497-504.

[12] Arif AE, Hassoun AS. An intestinal parasite survey among food handlers in Bhaghdad-1966. Bull Endem Dis (Baghdad) 1969; 11(1): 7-27.

[13] Okpala I. A survey of the incidence of blood, urinary and intestinal parasites among students and the kitchen personnel of the University of Nigeria, Nsukka. West Afr Med J Niger Pract 1971; 20(3): 260-262.

[14] Reyes H, Olea M, Hernandez R. Enteroparasitoses among food handlers in the eastern public health sector of Santiago. Bol Chil Parastolo 1972; 27(3): 115-116.

[15] Dall'Orso LM, Pinilla N, Parra G, Bull F. [Intestinal parasites and commensal protozoa in food handlers from the central area of the city of Concepcion, Chile (author's transl)] Bol Chil Parastol 1975; 30(1-2): 30-31.

[16] al-Lahham AB, Abu-Saud M, Shehabi AA. Prevalence of Salmonella, Shigella and intestinal parasites in food handlers in Irbid, Jordan. J Diarrhoeal Dis Res 1990; 8(4): 160-162.

[17] Sanches JL, Rios C, Hernandez-Fragoso I, Ho CK. Parasitological evaluation of a foodhandler population cohort in Panama: risk factors for intestinal parasitism. Mil Med 1990; 155(6): 250-255.

[18] Robinson RD, Murphy EL, Wilks RJ, Neva FA, Terry SI, Hanchard B, Figueroa JP, Blattner WA. Gastrointestinal parasitic infection in healthy Jamaican carriers of HTLV-I. J Trop Med Hyg 1991; 94(6): 411-415.

[19] Belhadj S, Souissi Z, Khaled S, Kooli J, Kennou, MF, Ben Rachid MS. [Intestinal parasitic diseases among food handlers] Tunis Med 1994; 72(6-7): 426-428.

[20] Costa-Cruz JM, Cardoso ML, Marques DE. Intestinal parasites in school food handlers in the city of Uberlandia, Minas Gerais, Brazil. Rev Inst Med Trop Sao Paulo 1995; 37(3): 191-196.

[21] Sadek Y, el-Fakahany AF, Lashin, AH, el-Salam FA. Intestinal parasites among foodhandlers in Qualyobia Governorate, with reference to the pathogenic parasites blastocystis hominis. J Egypt Soc Parasitol 1997; 27(2): 471-478.

[22] Wiwanitkit V, Assawawitoontip S. High prevalence of positive culture and parasites in stool samples of food handlers in a Thai hospital setting. MedGenMed 2002; 4(2): 8. 
الإصـابة بالطفيليات المعوية بين العاملين في مجال الغذاء بمكة

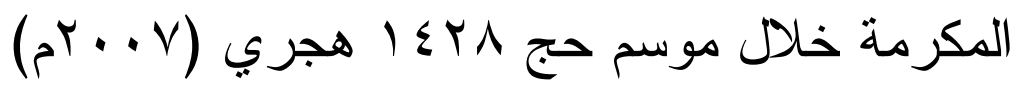

ماجد حددي واكد، وعصام إبر اهيم أزهر، و طارق عبدالله ظقر'

قسم تقنية المختبرات الطبية ، جامعة الملك عبدالعزيز ، جدة ،

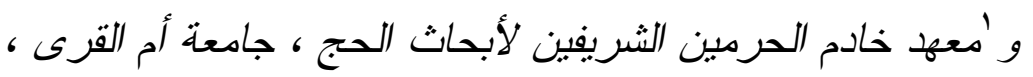
مكة المكرمة، المملكة العربية السعودية

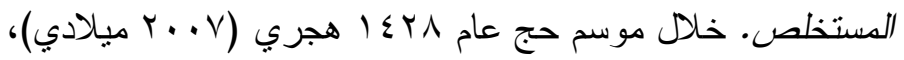

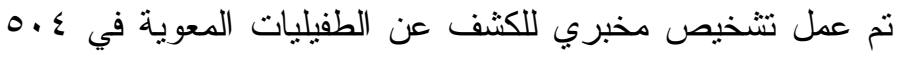
عامل في مجال الغذاء، من واحد وعشرين دولة. تم فحص عينات البراز باستخدام تقنية الثريحة المباشرة، وتقنية ريتشي المركزة

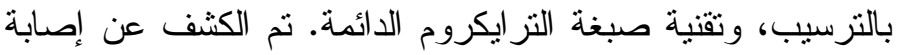

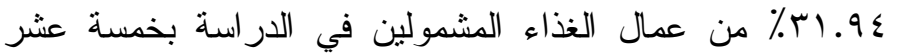

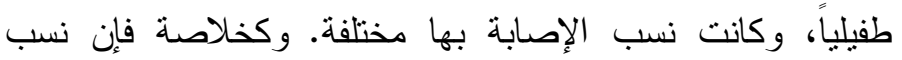
الإصابة المرتفعة، تحتم عمل تحليل للبراز للكثيف عن الإصابة بالطفيليات المعوية بشكل دوري، بالإضافة لعمل برامج توعية الإنية صحية عن النظافة الثخصية، موجهة للعاملين في مجال الغذاء

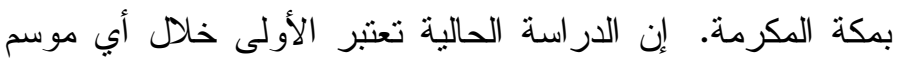
حج تعني بانتشار الطفيليات المعوية بين العاملين في مجال الغذاء الأي في العاصمة المقدة مكة المكرمة. 